\title{
Monitoring and analysis of the performance data of a RO-PAX ship in the perspective of energy efficiency
}

\author{
Anna Maria Galli, Prof. \\ Paola Gualeni, Assoc. Prof. \\ Giuseppe Stranieri, M. Sc. \\ Università degli Studi di Genova, Italy \\ Stefano Qualich, \\ Giovanni Cusano \\ Cetena S.p.A., Italy
}

\begin{abstract}
The rising cost offuel, the more and more severe international standards and a growing awareness of the environmental impact of pollutant emissions have led energy efficiency to become a theme of great interest in the marine sector. The strategy for increasing energy efficiency may refer both to the consumption reduction and to the increase of energy recovery systems. This need turns out in monitoring and control strategies for energy processes on board. Monitoring information is recorded and stocked in a database, that needs to be analyzed to find out patterns in large data sets. A huge amount of data, from a RO-PAX ship, has been analyzed in order to gain a further insight into ship performances. Improvements in ship energy performances could be reached with an intense study of the historical data of the vessel attitude.
\end{abstract}

Keywords: energy; efficiency; monitoring; trim; consumption

\section{INTRODUCTION}

Given the contest of ship energy efficiency management, the goal of this work is an attempt to study how propulsion and energy efficiency it is influenced by various parameters, i.e. trim, speed and displacement.

The data used in this study were collected by CETENA S.p.A. as part of ship consumption monitoring and control carried on a Ro-Ro Passenger ship $[1,2]$.

\section{SHIP DESCRIPTION AND DATA MANAGEMENT}

The ship sails in the Mediterranean sea and is able to carry 215 cars, 3000 lane meters of vehicles on road and can accommodate 2,300 passengers.

Propulsion is provided by four 4-stroke diesel engine (Wartsila 12V46D) capable of delivering a maximum power of $13,860 \mathrm{~kW}$ each one.

The propulsive scheme adopted consists in connecting each pair of engines, through a gear-box, to the axis, which ends with a variable pitch propeller with four blades. There is also a power take off (PTO), to produce electrical power during navigation.

In fig. 1 a simplified scheme of the propulsive plant installed on board is shown.

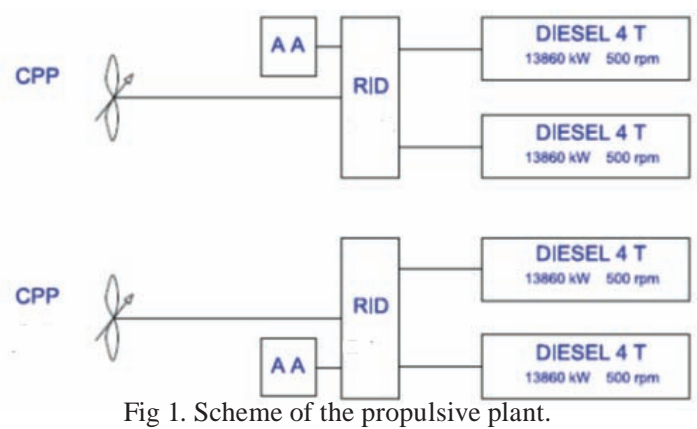

Main data of the ship are shown in table 1.

Tab 1. Main data of the ship.

\begin{tabular}{|c|c|}
\hline Length overall $\mathrm{L}_{\mathrm{OA}}$ & $225 \mathrm{~m}$ \\
\hline Breadth B & $30.4 \mathrm{~m}$ \\
\hline Design draught T & $7 \mathrm{~m}$ \\
\hline Design displacement $\Delta$ & $26500 \mathrm{t}$ \\
\hline $\mathrm{C}_{\mathrm{B}}$ & 0.57 \\
\hline & 4 engines \\
Propulsion & $12 \mathrm{~V} 46 \mathrm{D}$ \\
& Wartsila \\
\hline Maximum speed & 28 knots \\
\hline
\end{tabular}


The examined ship operates along three different routes: the first one covers a distance of 440 miles in nearly 19 hours of navigation along the whole year and the others cover each a distance of 168 miles and 293 miles, in respectively about 7 and 11 hours during only summer season (in practice a stop amid the whole-year route is placed in).

The ship is provided with a monitoring system designed, implemented and installed by CETENA that records a significant amount of variables; in table 2 there is a summary of the main parameters available from the automation system on board.

For each quantity the automation system provides a value every 20 seconds and then the monitoring system makes the average on 5 minutes and records it in a proper file.

Further, based on speed and GPS system, the system recognizes the arrival in a harbour and subdivides files according to ship trips. Data files are automatically send to Shipowner via e-mail or ftp connection, thus the energy manager onshore is continuously updated on ship's performance and management. The main panel of the software managing the acquisition, analysis and recording of ship data is shown in fig.2:

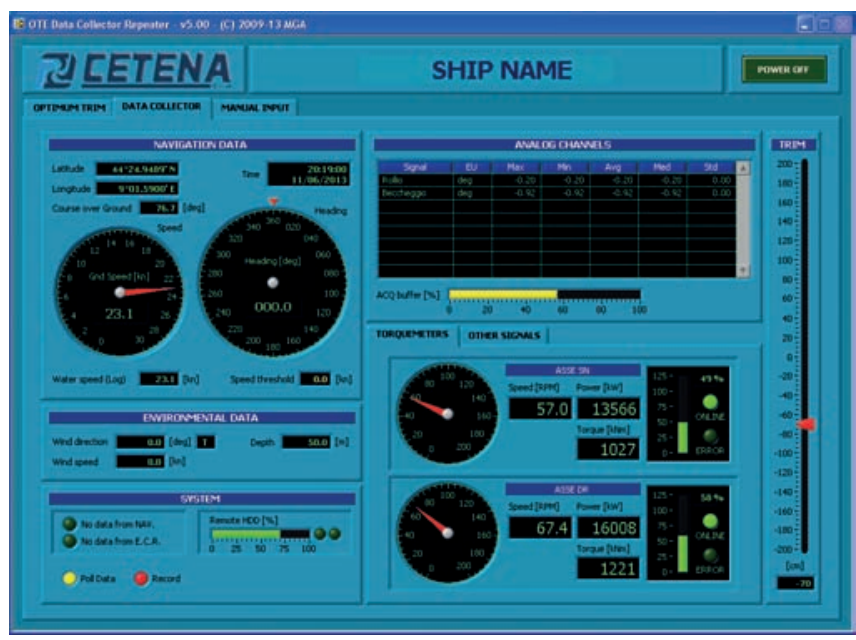

Fig 2. Main panel of the Performance Monitoring System by CETENA

In addition, inclinometers were installed (together proper acquisition hardware) and calibrated by CETENA to sign a positive trim when the ship is down by bow, negative when down by stern.

The full block diagram of the monitoring system is shown in fig. 3.

As easy guessed by the amount of items listed in the table, each trip is associated with a large number of data which represents an important source of information on the attitude and performance of the ship. On the other hand, however, there is a collection of large amount of data relating to different aspects of the ship (such as the analysis of consumption, the performance of the main engines and generators, the planning of their maintenance, the management of ballast, etc. ... ). The challenge is to make the proper synthesis and use of this large amount of data.
Tab 2. Main variables and tools adopted for the acquisition of travel data.

\begin{tabular}{|l|}
\hline Date, time \\
\hline Latitude, Longitude \\
\hline $\begin{array}{l}\text { Vector Track - Speed Over Ground } \\
\text { (VTG) }\end{array}$ \\
\hline Course Over Ground (COG) \\
\hline Ship speed \\
\hline Wind speed and direction \\
\hline Route \\
\hline Draught (3 measurements + Mean \\
and Standard Deviation) \\
\hline $\begin{array}{l}\text { Shaft power (1 measurement per } \\
\text { shaft) }\end{array}$ \\
\hline $\begin{array}{l}\text { Shaft revolutions (1 measurement } \\
\text { per ME) }\end{array}$ \\
\hline $\begin{array}{l}\text { MMEE and DDGG Fuel consumption } \\
\text { (1 measurement per DDGG }+1 \\
\text { measurement per shaft) }\end{array}$ \\
\hline $\begin{array}{l}\text { DDGG Power and Shaft generator (1 } \\
\text { measurement per DG }+1 \text { per SG) }\end{array}$ \\
\hline $\begin{array}{l}\text { MMEE Temperature (1 measurement } \\
\text { T feeding air }+2 \text { probes per each ME) }\end{array}$ \\
\hline $\begin{array}{l}\text { Exhaust gas temperature (1 } \\
\text { measurement Per ME) }\end{array}$ \\
\hline $\begin{array}{l}\text { MMEE Pressures (1 measurement per } \\
\text { ME) }\end{array}$ \\
\hline $\begin{array}{l}\text { MMEE Running time (1 measurement } \\
\text { per ME) }\end{array}$ \\
\hline Sea temperature \\
\hline $\begin{array}{l}\text { HFO and MDO fuel level (15 } \\
\text { measurements) }\end{array}$ \\
\hline Lube oil level (6 measurements) \\
\hline
\end{tabular}

The followed procedure consists of the assumed methodology to make the average of these values on the navigation time.

Within each trip it is useful to divide the time frame of the monitored parameters in successive stages:

- Load Pre-Departure - propulsive quantities have little significance, while draughts and trims have large fluctuations related to the loading / unloading and weight transfer typical of the loading and unloading phases.

- Departure Manoeuvre - there is a transient phase for all quantities, with gradually increasing speed and power

- $\quad$ Navigation - quantities are around their cruising values, monitoring data recorded at this stage represent the starting point for all sequent analysis.

- Arrival Manoeuvre - this phase is characterized by a transient, decreasing with speed and power. 


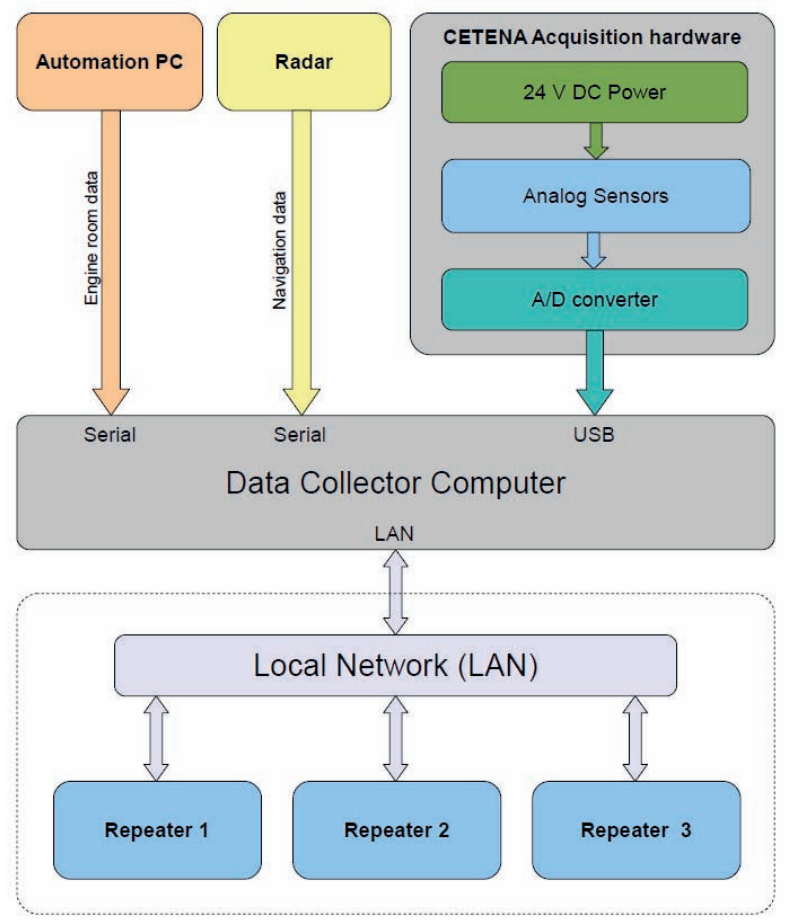

Fig 3. Full block diagram of the monitoring system

As easy guessed by the amount of items listed in the table, each trip is associated with a large number of data which represents an important source of information on the attitude and performance of the ship. On the other hand, however, there is a collection of large amount of data relating to different aspects of the ship (such as the analysis of consumption, the performance of the main engines and generators, the planning of their maintenance, the management of ballast, etc. ... ). The challenge is to make the proper synthesis and use of this large amount of data.

The followed procedure consists of the assumed methodology to make the average of these values on the navigation time.

Within each trip it is useful to divide the time frame of the monitored parameters in successive stages:

- Load Pre-Departure - propulsive quantities have little significance, while draughts and trims have large fluctuations related to the loading / unloading and weight transfer typical of the loading and unloading phases.

- Departure Manoeuvre - there is a transient phase for all quantities, with gradually increasing speed and power

- Navigation - quantities are around their cruising values, monitoring data recorded at this stage represent the starting point for all sequent analysis.

- $\quad$ Arrival Manoeuvre - this phase is characterized by a transient, decreasing with speed and power.

In Fig 4 and Fig 5 time distributions of some variables recorded are shown for a selected trip. To highlight the adopted subdivision, a bar is shown representing the different stages of the journey.

For the study carried out in this paper, navigation data are mainly used. Values measured during the manoeuvre have to be excluded since they may be associated with abrupt variations due to transient motions, as shown in figures 4 and 5. Loading phase data, on the other hand, are partially used for the definition of some static quantities, as the static trims or draught, from which it is possible to gather arrival and departure displacements.

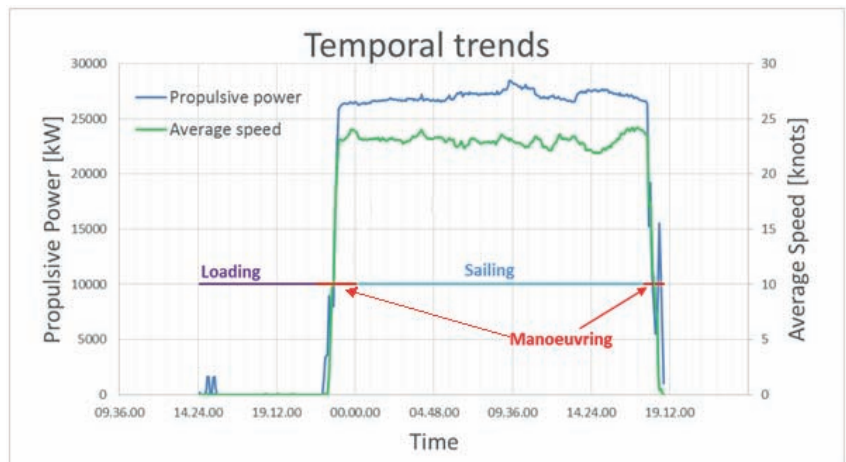

Fig 4. Temporal distributions of the propulsive power and average speed for a voyage.

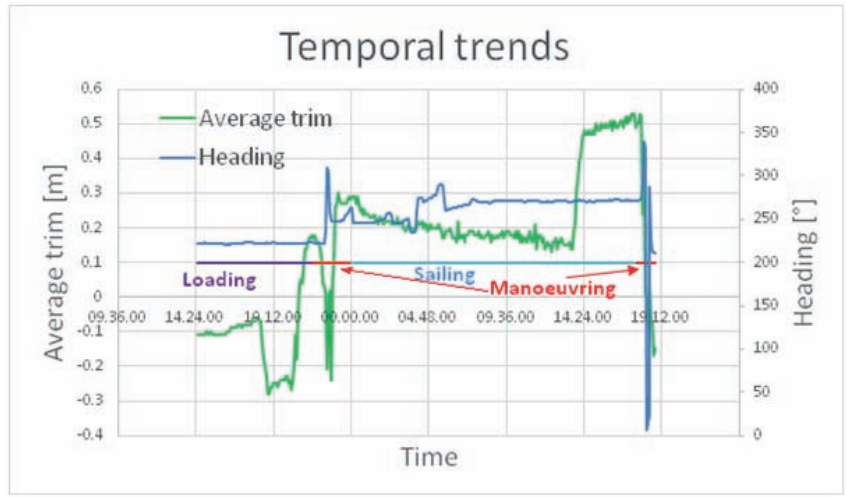

Fig 5. Temporal distributions of the average trim and route for the same voyage of

\section{TIME DISTRIBUTIONS VS AVERAGE VALUES}

\section{ADOPTED QUANTITIES}

Describing the performance of a ship and trying to find the correlation between the great amount of available timevarying quantities could be complex as the voyages are characterized by variable periods of navigation (also on the same route) and the duration of the loading phase varies (in an almost random way) from trip to trip, regardless of the route.

It could be useful describing the voyages, or rather, periods of navigation of each journey (from now on voyage will strictly refer to the corresponding phase of navigation) through averaged quantities. There is, indeed, the necessity of referring to a single value for each quantity, so as to be able to compare among them voyages pertaining to the same sample through scatterplots and not only as a function of time.

In the perspective of investigating the influence of trim on the propulsive quantities, not all available data are necessary. 
Then it is possible to make a selection, choosing only quantities that reasonably could affect ship performance.

Below there is a list of selected variables, with a brief description of their meanings and, where necessary, the formulation adopted to achieve them.

- $\quad$ Average propulsive power [kW]: it is the power supplied by 4 main engines, as a time weighted average over the period of navigation

- $\quad$ Average Navigation speed [Kn]: it is the weighted average of the speed values recorded during navigation

- Fuel consumption per hour $(\mathrm{FCH})\left[\frac{m^{3}}{h}\right]$ : it is used to achieve a measure of consumption independent of the navigation duration, which expresses the time weighted average of fuel flow rate (measured by the flow meter), delivered to the engine propulsion

- Average Navigation consumption $\mathrm{m}^{3}$ : it represents the $\mathrm{FCH}$ multiplied by the hours of navigation

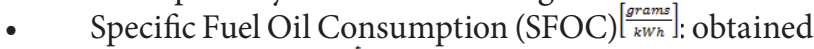
from the (1), with $\rho_{\text {FUEL }}=0.92 \frac{t}{m^{s}}$, as:

$S F O C=10^{6} \cdot\left(\frac{\text { Average consumption per hour }}{\text { Average propulsive power }}\right) \cdot \rho_{\text {COMB }}$

- $\quad$ Static trim at the departure [m]: the very last static trim value immediately before the beginning of navigation. It is defined by:

$$
\text { Trim dep }=T_{\text {FORE dep }}-T_{\text {AFT dep }}
$$

- $\quad$ Static trim at the arrival $[\mathrm{m}]$ : the very first static trim value immediately after the end of navigation. It is defined by: :

$$
\text { Trim arr }=T_{\text {FORE arr }}-T_{\text {AFT arr }}
$$

- $\quad$ Average static trim $[\mathrm{m}]$ : the arithmetic mean of static trim at departure and at arrival

$\operatorname{Trim}_{\text {AVERAGE STATIC }}=\frac{\operatorname{Trim}_{\text {DEPARTURE }}+\operatorname{Trim}_{\text {ARRIVAL }}}{2}(4)$

- $\quad$ Difference of static trim [m]: the difference of static trim between arrival and departure

Static Trim Difference $=$ Trim $_{\text {ARRIVAL }}-$ Trim $_{\text {DEPARTURE (5) }}$

- $\quad$ Average Dynamic trim [m], after called Trim ${ }_{D Y N}$ AVER., represents the weighted average of trim measured by inclinometers, carried out over the period of navigation. It refers, therefore, to the dynamic attitude of the ship in wave field.
- Dynamic residual trim [m]: the ,'real" dynamic trim, according to the (5):

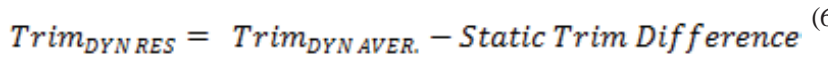

- Displacement at the departure [t]: from the hydrostatics tables, entering with average draught at the departure.

- Displacement at the arrival $[\mathrm{t}]$ : it is the displacement corresponding to the last pair of draughts $\mathrm{T}_{\mathrm{FORE}}$ and $\mathrm{T}_{\mathrm{AFT}}$ recorded during the arrival manoeuvring and with ship already in port

- $\quad$ Average displacement [t]: the arithmetic mean of the first two items, given by:

$$
\Delta_{\text {AVERAGE }}=\frac{\Delta_{\text {DEPARTURE }}+\Delta_{\text {ARRIVAL }}}{2}
$$

- Difference of displacement [t]: the difference of displacement between arrival and departure, given by:

$$
\text { Difference } \Delta=\Delta_{\text {ARRIVAL }}-\Delta_{\text {DEPARTURE }}
$$

- $\quad$ Route $\left[^{\circ}\right]$ : the route in terms of average value (weighted average) calculated on the navigation period

- Wind direction $\left[{ }^{\circ}\right]$ : the absolute wind direction is expressed as a weighted average of the values monitored during the navigation

- Wind intensity [knots]: it is the weighted average of the data recorded during the navigation period

- Hours of navigation [h]: this quantity represents the duration of the navigation.

It is interesting to note the importance of introducing and analysing different definitions of displacement and trim. The ship displacement is continuously changing along the trip because of for example consumable reduction. Therefore it have been introduced the average displacement and the difference of displacement between arrival and departure.

Referring to trim, indeed, it is possible to define three quantities, linked to each other, but with different meanings: - Static trim: it is a variable that, within a certain range, can be controlled by the crew, depending on the weight of the ship and its distribution; it can be changed with appropriate transfers or loading / unloading of weight (for example, ballasting) and represents the quantity adjustable by the crew during the loading, before the vessel leaves the port.

- Dynamic trim: neglecting the transients associated with the phases of manoeuvre, this quantity is the longitudinal inclination that the ship assumes dynamically during navigation. Despite descending from static trim, the dynamic one is not a controllable variable, since it depends on vessel speed and geometry. Moreover there is also a variation due 
to the ship motion in relation with the sea state. In principle a steady dynamic trim and an unsteady dynamic trim it should be defined. It is possible to measure dynamic trim through specific acquisition systems (such as three inclinometers one at bow, one at middle-ship, and one at stern, installed onboard the considered ship in order to obtain reliable values).

- $\quad$ Residual dynamic trim: This quantity, according to the (5), has been derived by subtracting to the measured dynamic trim the variation of the static one, which, during the navigation, is due to the decrease of the consumables and to the consequent variation of the weight distribution.

Trying to make clear the differences between the adopted definitions, the trends of dynamic trim and residual dynamic trim for a voyage of the ship are shown in Fig 6 (the same voyage adopted for the previous trends examples).

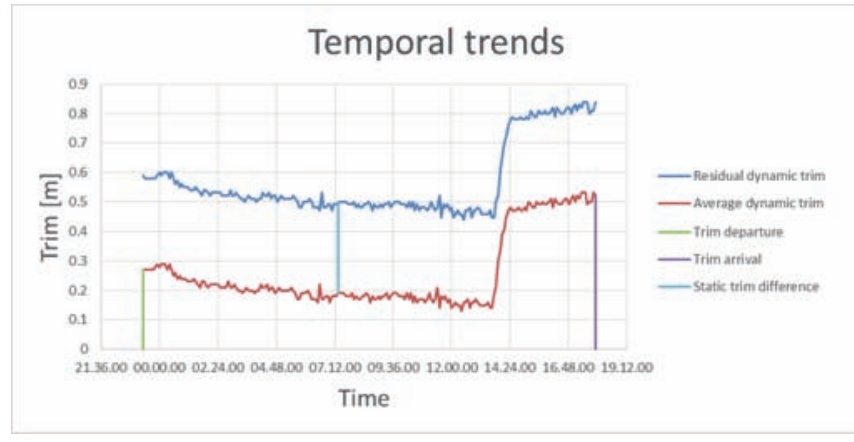

Fig 6. Temporal trends of dynamic trim and residual dynamic trim for a voyage.

\section{DATA SELECTION AND ANALYSIS}

The database of navigation data is composed of data transmitted to the technical office by the monitoring system, relative to a year of navigation (286 voyages).

Since it may happen that for some voyages there are missing data and some variables show values out of range, probably due to an incorrect calibration (or malfunction) of some measuring instruments, after a preliminary check, anomalous quantities are excluded from the sample.

The available data (228 voyages) do not represent a homogeneous sample, as they are related to all the routes, they do not distinguish on the basis of navigation speed and they consider all the wind states that the ship has encountered during the year.

A visual representation of the heterogeneity of the samples can be achieved by using normalized histograms, of subtended unitary area.

The following figures (Fig. 7 to Fig. 10) show histograms of the propulsive power, navigation speed, dynamic residual trim and average displacement for the entire sample.

The propulsive power has values between $25000 \mathrm{~kW}$ and $45000 \mathrm{~kW}$, corresponding respectively to $45 \%$ and $81 \%$ of the maximum output power from the main engines (equal to $55440 \mathrm{~kW}$ ). Data do not show a distribution around a single average value, but there are three main power levels
$(27500 \mathrm{~kW}, 38500 \mathrm{~kW}$ and $43000 \mathrm{~kW})$ around which values are distributed with a certain dispersion. The histogram obtained, however, is not in contrast with the physical meaning of the data, as these contain information about all-year voyages relevant to three different routes and therefore represent a heterogeneous sample.

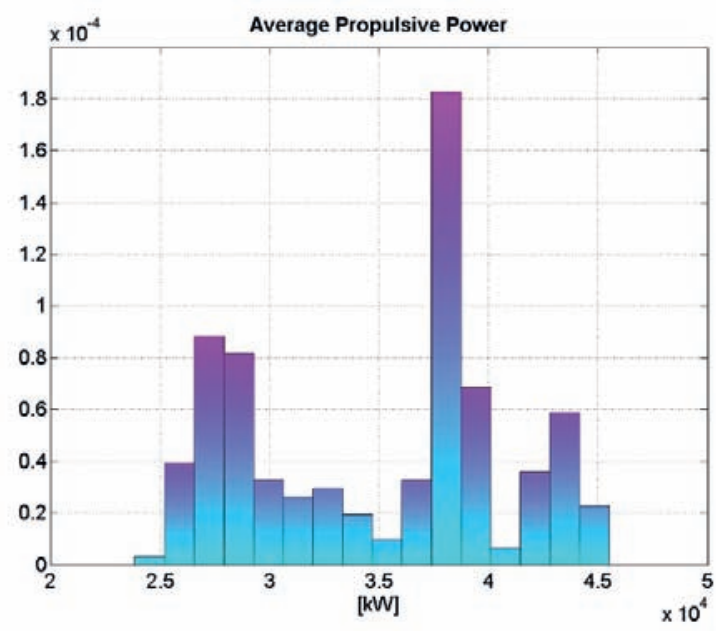

Fig. 7. Average Propulsive power distribution.

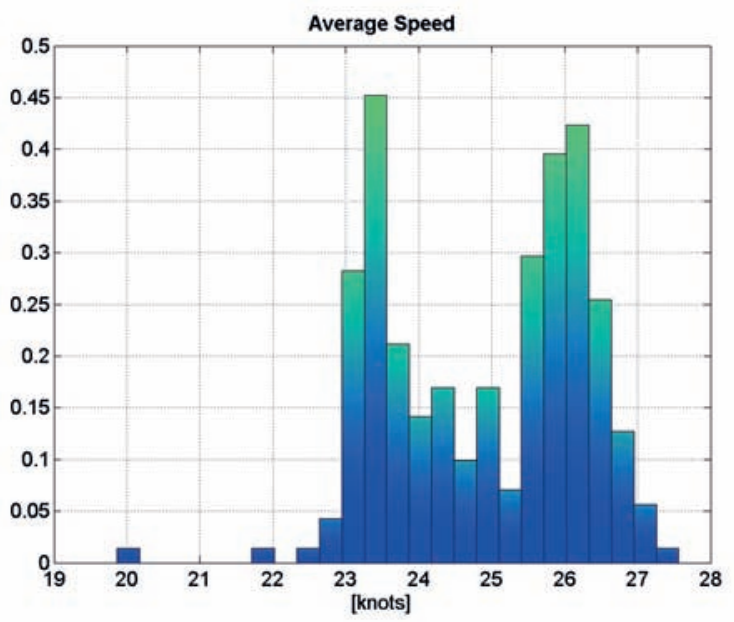

Fig. 8. Average speed distribution.

Also the speed (FIG 8) is not distributed symmetrically around a single average value, but it has two groups of data that may be associated with two „bell” shapes with tails overlapping. From the histogram it can be deduced that there are two prevailing speeds (respectively 23.5 and 26.5 knots) around which are distributed all the data of the year.

In contrast to power and speed, the dynamic residual trim (Fig. 9) has an average value (about $60 \mathrm{~cm}$ by-stern trim), around which all data of the year are distributed, even if in a non-symmetrical way and with the presence of some nonhomogeneous data, varying between a minimum value of about 2 meters by-stern trim and a maximum of about 50 $\mathrm{cm}$ by-bow trim. 


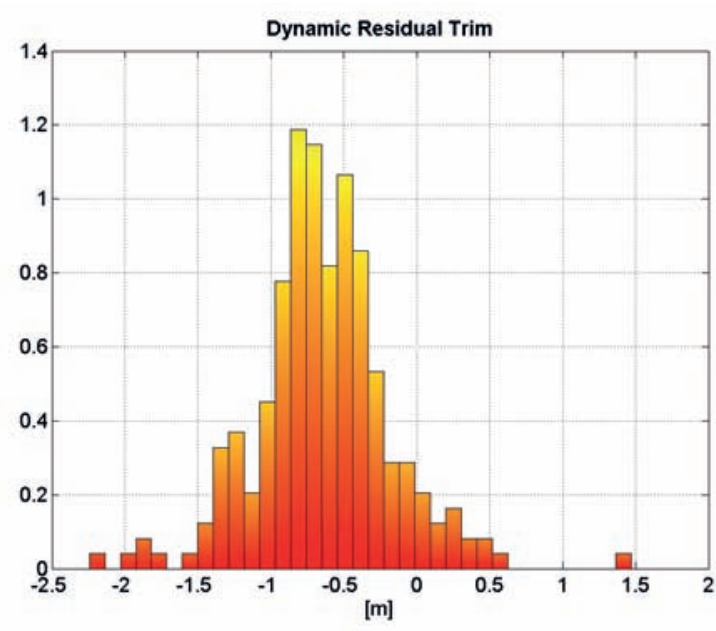

Fig. 9. Dynamic residual trim distribution.

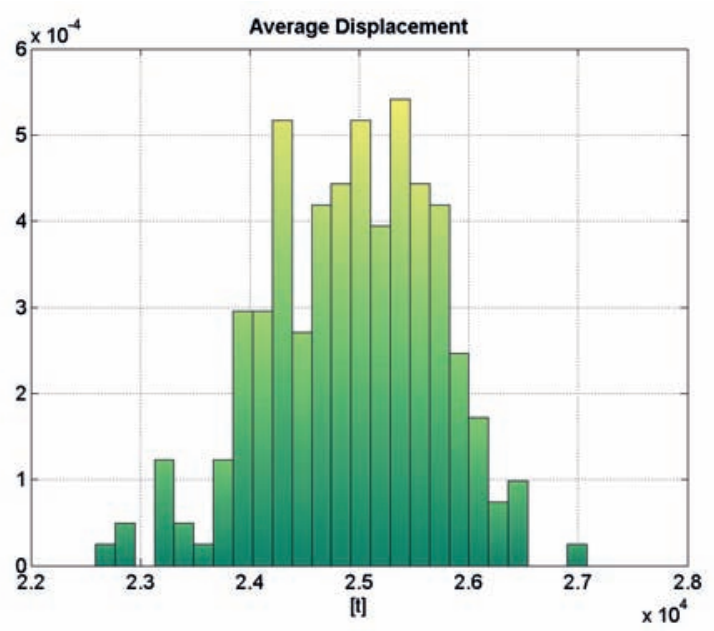

Fig. 10. Average displacement Distribution.

Similar to the residual dynamic trim, the displacement (Fig. 10) presents a histogram with a regular distribution (between a minimum value of about $22500 \mathrm{t}$ and a maximum of about $27000 \mathrm{t}$ ), almost symmetric respect to the average value, equal to $25000 \mathrm{t}$.

The trends observed in the histograms shown in Fig. 7 and Fig. 8 suggest that, in an attempt to achieve homogeneous subsets of variables, it can be useful to further subdivide the sample in terms of average speed and propulsive power, in order to analyse data separately for different groups.

It is worth to remind that the short routes cover distances that are significantly shorter than the long (respectively 168 and 293 miles against 440) and also navigation times are considerably lower (7 and 11 hours versus 19).

The analogy in terms of speed and propulsive power and the relationship that links them to the "long route", allow to consider the data of the short routes as a single statistical sample.

This assumption makes it easier to separate the data that, at this point, are classified into the following two categories:
- Long routes - all data of the long voyages, regardless of the navigation direction. The sample consists of 65 trips.

- Short routes - all data of the short voyages, regardless of the navigation direction. The sample consists of 91 travel.

A further selection has allowed to exclude the weather conditions and the navigation direction from the variables considered for the analysis of the relationship between trim and propulsive variables (speed, power and fuel consumption). The following analysis is aimed, therefore, to investigate the relationships between the different definitions of trim and propulsive quantities for the selected sample. The process of selection and analysis carried out showed that the data can be divided into three distinct classes, according to the percentage of maximum power at which they are associated, as shown in the following table 3.

All the data referring to the long route voyages belong to the first class, regardless of the navigation direction and seasonality, while data referring to the short route voyages are divided on the other two classes: Class 3 contains voyages carried out in July, while the remaining voyages belong to Class 2.

Tab. 3. Subdivision adopted for the analysis

\begin{tabular}{|l|r|r|}
\hline \multicolumn{1}{|c|}{ Identification } & \% P MAX & No. of voyages \\
\hline Class 1 - Long routes & $\mathrm{P}<65 \%$ & 63 \\
\hline Class 2 - Short routes & $65 \%<\mathrm{P}<75 \%$ & 63 \\
\hline Class 3 - July short routes & $\mathrm{P}>75 \%$ & 30 \\
\hline \multicolumn{2}{|r|}{ total number of voyages } & $\mathbf{1 5 6}$ \\
\hline
\end{tabular}

In Fig. 11 data of the selected sample (156 trips) are shown, divided according to class.

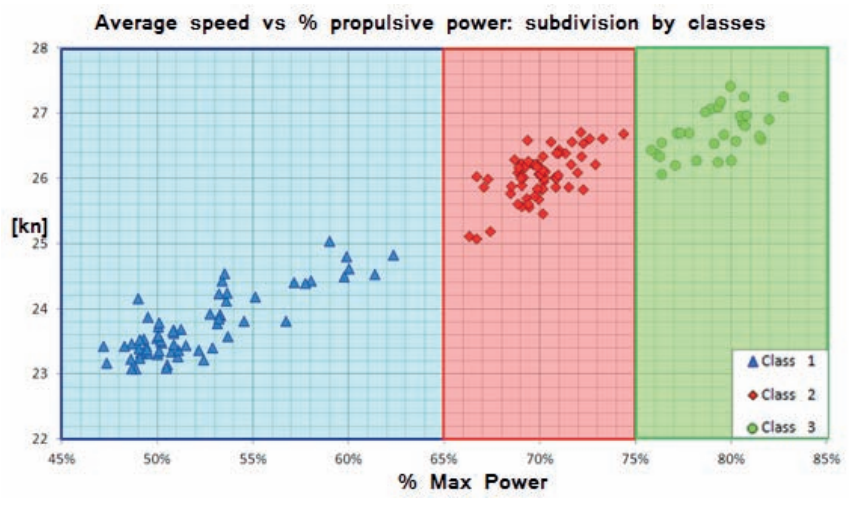

Fig. 11. Subdivision by classes

In order to analyse data, in this paper it has been decided to consider a static definition of trim (intuitively given by the static departure trim, which represents the variable tuneable by the crew), two dynamic definitions (given by the average dynamic trim, which represents the variable directly measured during the navigation and the residual dynamic trim), the speed, the propulsive power and the consumption (expressed in terms of SFOC and calculated from the measured power). 
In this paper we are going to present only results referring to Class 2, ie those referring to the short routes, excluding July data as already said. Class 1 data are referred to long routes, during which performance percentages can vary a lot during each trip: mean trip data are thus less significant and not presented in this paper.

\subsection{Class 2 - Short routes}

The first scatter diagram shows the dynamic residual trim as a function of static trim at the departure.

As shown in Fig. 12, they are characterized by a strong positive correlation $(\rho=0.92)$ and, albeit with some exceptions, the data sample is collected around the line of the Ordinary Least Squares.

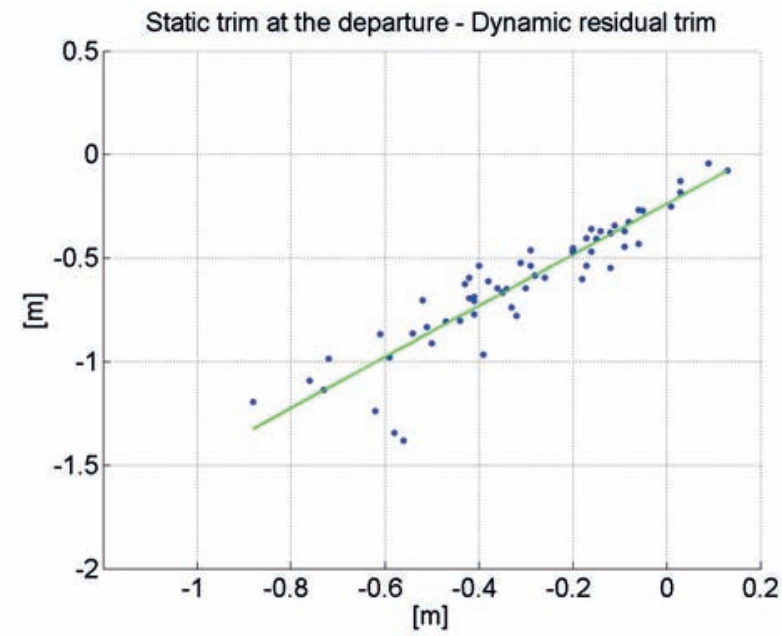

Fig. 12. Trends of the dynamic residual trim as a function of the static trim at the departure for Class 2

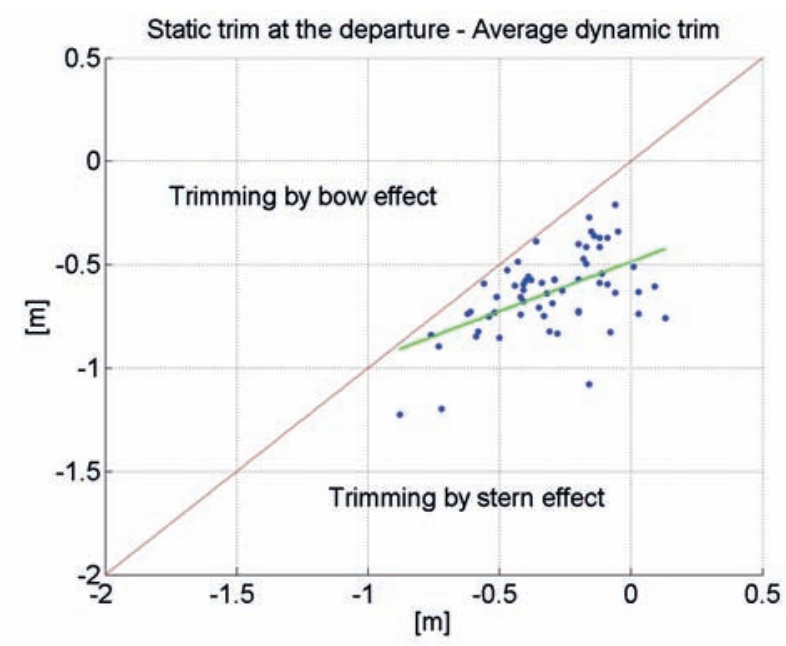

Fig. 13. Distribution of the average dynamic trim as a function of the static trim at the departure for Class 2

Reporting the data also in terms of average dynamic trim (Fig. 13), it is observed that the sample, although characterized by a dispersion greater than the previous display, still presents a good correlation $(\rho=0.53)$. it is also interesting to note that all points are on "the same side” of the bisector (drawn in gray) and have, therefore, an average dynamic trim lower than the corresponding static trim. This trend could be identified as a ship attitude to present a trim by stern when at cruise speed, as confirmed by the previous fig. 12 .

Data of the sample may also be reported by linking the static trim at the departure and the average propulsive power (Fig. 14).

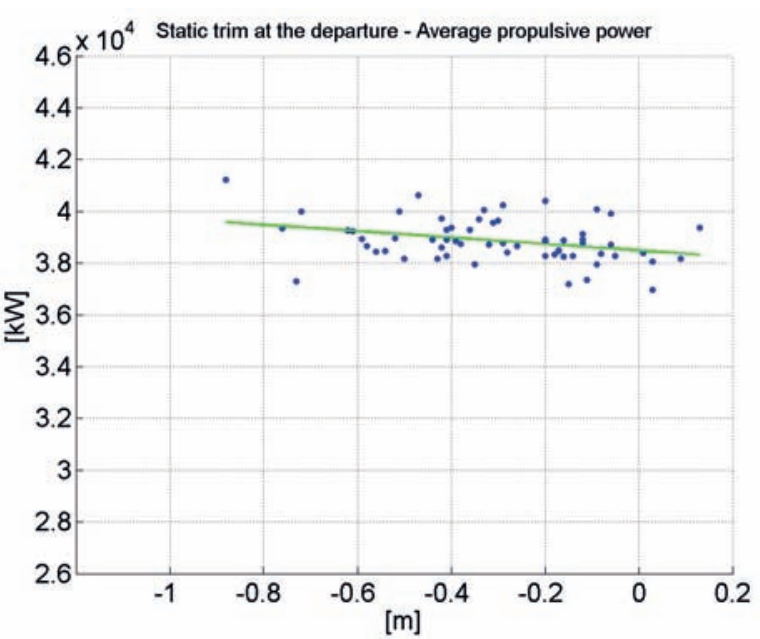

Fig. 14. Average propulsive power as a function of the static trim at the departure for Class 2

For static trims varying between $90 \mathrm{~cm}$ of trim-by-stern and $15 \mathrm{~cm}$ of trim-by-bow there are output powers ranging between $37000 \mathrm{~kW}$ and $41000 \mathrm{~kW}$, with a range of $10 \%$ of the reference power (average power of the sample), equal to $38900 \mathrm{~kW}$.

At first glance, it seems that the two variables are linked by a, albeit weak, negative correlation; Pearson's coefficient relative to the sample, in fact, is $\rho=-0.33$.

However, it is expected that the downward trend observed in the distribution of power is, at least partially, due to the trend of the average speed rather than to changes in the static trim.

So it is possible to conclude that for this sample it is difficult to observe a strong dependence of power from the static trim and the variations of the propulsive power are mainly to be attributed to the corresponding speed fluctuations. The same process is carried out for average dynamic trim (Fig. 15) and then, it is possible to conclude, also for the average dynamic trim, that a statistical relationship between this quantity and the propulsive power exists but is very weak and can't lead to set definitive conclusions.

In Fig. 16 is shown the trend of the specific fuel consumption as a function of the static trim at the departure.

As can be seen from the figure, the definition of SFOC presents a high dispersion and the consumption data vary between a minimum of about $195 \mathrm{~g} / \mathrm{kWh}$ and a maximum of $221 \mathrm{~g} / \mathrm{kWh}$, with an excursion equal to $12 \%$ of the reference value (average of the consumption data of the class) of 208 $\mathrm{g} / \mathrm{kWh}$. The sample appears to have a moderate positive trend, identified by a correlation coefficient equal to $\rho=0.28$. 
It is assumed, however, that the increasing trend observed for the distribution of specific consumption is due to the decreasing trend of the corresponding power data (Fig. 16). The value of the Pearson coefficient and the high dispersion of the sample do not allow to definitively conclude that a statistical relationship exists between the consumption data and the static trim.

The conclusion is reached as a result of the analysis of the performance of SFOC and is not surprising nor unexpected. It is evident, in fact, that consumption, albeit referred to units of energy, are strongly linked to the power values used to define them. It is, therefore, plausible that the low correlation between power and the trim is reflected in a similar behaviour in consumption.

Now we study the trend of the specific consumption as a function of the average dynamic trim.

In Fig 17 the trend of the SFOC (calculated from measured power) as a function of the trim dynamic is shown.

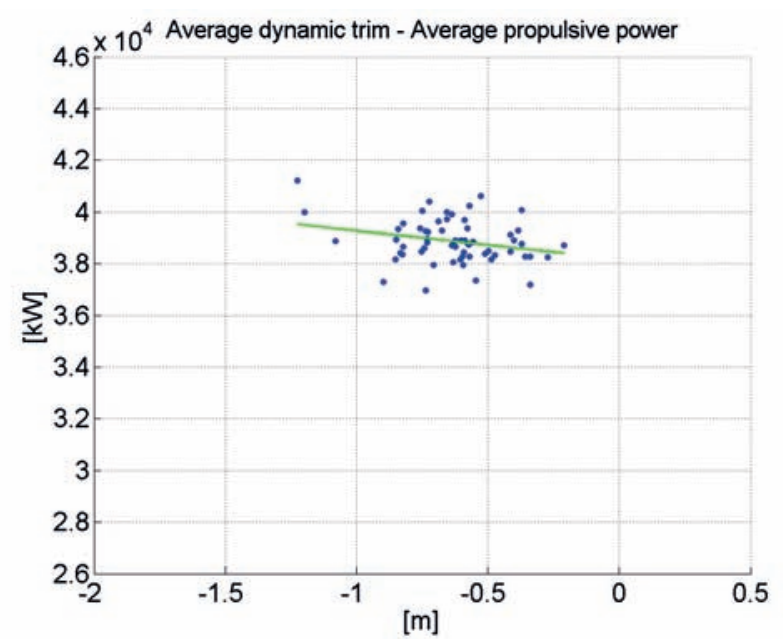

Fig. 15. Propulsive power as a function of the average dynamic trim for Class 2

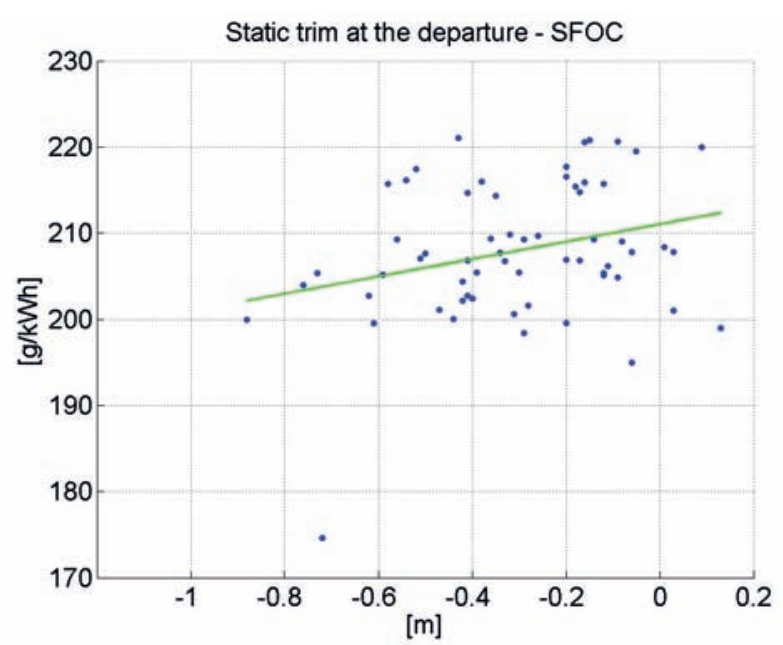

Fig. 16. Specific fuel consumption as a function of the static trim at the departure for Class 2.

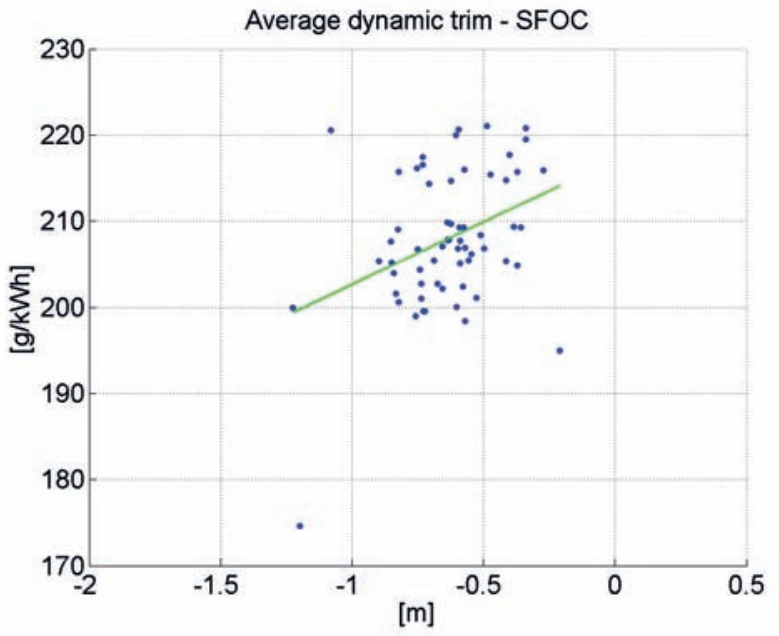

Fig. 17. Average dynamic trim as a function of SFOC for Class 2

It can be observed that the values of specific consumption are very dispersed. The moderate positive trend, expressed by a correlation coefficient equal to $\rho=0.36$, it would seem more attributable to the presence of some not homogeneous value than to an actual strong relationship between the two variables.

Due to the high dispersion of the sample and the moderate correlation between the specific consumption and the dynamic trim, it can be concluded that at the ship speeds measured in Class 2 routes the statistical relationship between the SFOC and the trim angle of the vessel during navigation is not so evident.

\section{CONCLUSIONS}

The recording of data for energy management is becoming increasingly widespread and then it is important to observe and have a defined control of the data, in order to have a clear view of those useful for an energetic analysis and to avoid collecting and elaborating unessential information .

In this paper, after some general analysis, we focused on the influence of trim. It was realised how is important to define different types of trim and, in particular, to observe on which kind of trim it is theoretically possible to intervene (static trim at the departure) and which is instead dependent on other quantities (dynamic trim during navigation).

Quantitative data were shown to highlight the variability of certain parameters such as draught and displacement, considering that often it is assumed that they are constant and instead they are variable during the navigation, for example due to the reduction of consumables.

Moreover, it has been find out that is difficult to extract a clear influence on trim and ship performance from data available at this state of the art Nevertheless it can be observed that SFOC has an increasing trend behaviour as a function of static trim at the departure and average dynamic trim for data referring to the Class 2 . 


\section{Acknowledgments}

Authors would like to express their sincere gratitude to Ing. Annalisa Bracco who gave a fundamental contribution to this work while developing her master graduation thesis job.

\section{REFERENCES}

1. Pescetto, A. \& L. Sebastian; "Energy management: a holistic operational strategy to enhance ship energy efficiency of ships in service". 2012

2. Pescetto, A. \& L. Sebastiani; "Monitoring systems: a strategic tool to enhance ship energy efficiency."2012

\section{CONTACT WITH THE AUTOR}

Anna Maria Galli,

Paola Gualeni,

Giuseppe Stranieri

DITEN,

Università degli Studi di Genova,

Via Montallegro 1

16145 Genova

ITALY

Stefano Qualich,

Giovanni Cusano

Cetena S.p.A.,

Via Ippolito d'Aste 5,

16121 Genova

ITALY 